\title{
A MULTIFORME OBRA ARTÍSTICA E INTELECTUAL DE THEODORO BRAGA
}

Edilson da Silveira Coelho

UFPA - UFRJ

Este trabalho aborda aspectos da obra artística e intelectual do paraense Theodoro Braga, produzida no período de 1905 a 1935. Neste período, marcado pela transição e afirmação da arte brasileira, ele se destacou no cenário artístico pela maneira diversificada com que produziu sua obra, bem como por lutar pela valorização da arte nacional.

Esquecida nos últimos 50 anos pelos estudiosos da arte brasileira, a obra de Theodoro Braga desperta hoje a curiosidade de historiadores e pesquisadores de arte. $\mathrm{O}$ significado literal do termo multiforme ${ }^{1}$ como sendo "aquilo que tem muitas formas" ganha força quando a referência é a obra de Theodoro Braga, pois, além de pintor, decorador, artista gráfico, designer e ilustrador, o artista percorreu também os caminhos da intelectualidade como crítico de arte, historiador, geógrafo, sociólogo, administrador e educador.

Autores brasileiros como Quirino Campofiorito ${ }^{2}$, Carlos Rubens ${ }^{3}$, Ana Mae Barbosa ${ }^{4}$ e Luiz Marques ${ }^{5}$ fazem referências à obra ou às idéias de Theodoro Braga, discutindo aspectos relevantes de sua trajetória artística e intelectual.

O paraense Clóvis Morais Rego, considerado seu principal biógrafo, publicou em 1974 a obra "Theodoro Braga: historiador e artista", registrando momentos da história e da influência social e artística que Theodoro exerceu na cidade de Belém do Pará nas três primeiras décadas do século XX.

1 FERREIRA, Aurélio Buarque de Holanda. Novo Aurélio Século XXI: o dicionário da língua portuguesa. $3^{\mathrm{a}}$ ed. Rio de Janeiro: Nova Fronteira, 1999.

2 CAMPOFIORITO, Quirino. A república e a decadência da disciplina neoclássica: 1890-1918. Rio de Janeiro: Pinakotheke, 1983, p.69.

3 RUBENS, Carlos. Pequena história das Artes Plásticas no Brasil. Edição Ilustrada. São Paulo: Nacional, 1941. Coleção Brasiliana, série $5^{\text {a }}$, vol. 198 - pp. 244-253

4 BARBOSA, Ana Mae. História da arte-educação no Brasil: das origens ao modernismo. São Paulo: Perspectiva, 1978.

5 MARQUES, Luiz. Trinta mestres da pintura no Brasil. São Paulo: Museu de Arte de São Paulo, 2001.

6 MORAIS REGO, Clóvis. Theodoro Braga: historiador e artista. Belém: Conselho Estadual de Cultura, 1974. 
Aldrin Figueiredo ${ }^{7}$, em tese defendida na UNICAMP (2001), analisa Belém no período entre 1908 e 1929, dando destaque à participação de Theodoro Braga como um dos principais articulistas de grupos de intelectuais que procuravam construir a chamada "identidade nacional" na qual a Amazônia passaria a ser, necessariamente, uma espécie de epicentro intelectual do país.

Em 2003, Edison Farias defende em sua tese "Calor, chuva, tela e canivete - a pintura no tempo do modernismo em Belém"8 (ECA-USP) a importância do artista Theodoro Braga na criação das matrizes dos Salões das Artes Plásticas em Belém, quando incentivava os educandos para uma "educação da sensibilidade" por meio das exposições de seus trabalhos de arte.

Patrícia Bueno Godoy (2005) ${ }^{9}$ estuda a obra de Theodoro Braga A Planta Brasileira (copiada do natural) - Aplicada à Ornamentação, considerando-a uma das maiores representações do design ornamental brasileiro, pela reprodução dos elementos da flora, organizados de acordo com a técnica dos ilustradores botânicos, e pelos ornamentos criados a partir dos originais da natureza que se apresentam sob nítida inspiração art nowveau.

\section{A Formação Artística e Intelectual}

Nascido em Belém do Pará no ano de 1872, época em que florescia o Ciclo da Borracha na Amazônia, ainda jovem, Theodoro Braga mudou-se para a cidade de Recife, onde percorreu diferentes caminhos da cultura humanista. Formou-se bacharel em Direito e, construiu o que poderíamos chamar de personalidade artística pela instrução de Jerônimo José Telles Junior, famoso paisagista da época.

Em 1894, mudou-se para o Rio de Janeiro onde estudou na Escola Nacional de Belas Artes, refinando seu talento para o desenho e a pintura

7 FIGUEIREDO, Aldrin. Eternos modernos: uma história social da arte e da literatura na Amazônia, 1908-1929. Tese de Doutorado. Campinas: UNICAMP, 2001.

8 FARIAS, Edison da Silva. Tela, chuva, canivete: a pintura de Belém no tempo do modernismo. Tese de Doutorado. São Paulo: ECA, 2003.

9 GODOY, Patrícia Bueno. Arte decorativa brasileira: Theodoro Braga e A planta brasileira (copiada do natural) - aplicada à ornamentação. Campinas, 2005.

BRAGA, Theodoro A planta brasileira (copiada do natural) - aplicada à ornamentação. Texto e Aquarelas. Belém, 1905. 
pelas mãos de Belmiro de Almeida, Daniel Bérard e Zeferino da Costa. Aluno brilhante, obteve durante todo o curso o destaque de "aprovado com distinção", conceito máximo na Academia. Sua busca constante pelo aprimoramento na pintura, impulsionou-o para ir mais longe ainda: no ano de 1899, submeteu-se às provas do concurso para a conquista do Prêmio de Viagem para a Europa, no que foi não só aprovado, como recebeu a indicação para estudar em Paris.

Então, como pensionista da Escola Nacional de Belas Artes, Theodoro Braga fixou-se em Paris nos anos de 1900 a 1905, para cursos na Academia Julian, onde estudou com Jean-Paul Laurens, artista emblemático da arte acadêmica francesa, com Benjamin Jean Joseph Constant, mestre na pintura decorativa e retratística, e com Henry-Paul Royer, pintor de gênero, retratista e paisagista ${ }^{10}$. Nessa sua passagem por Paris, em busca de experimentar as novas linguagens que se ofereciam, manteve contato com a arte decorativa francesa, possivelmente a produzida por Éugene Grasset, famoso artista considerado uma das mais destacadas expressões do Art Nouveau na França. ${ }^{11}$

\section{O caminho de volta e a afirmação profissional}

Em 1905, depois de cumprir o período em que esteve como pensionista da Escola Nacional de Belas Artes, Theodoro Braga fez o caminho de volta, realizando exposições de seus trabalhos, inicialmente no Rio de Janeiro, depois em Recife e, por último, em Belém, aonde sua obra vinha sendo aguardada com grande expectativa pela sociedade.

No início do século XX, Belém vivia a euforia da Belle Époque paraense conduzida pelo então intendente Antonio Lemos o qual, mais tarde, viria a ser uma espécie de mecenas da obra ${ }^{12}$ de Theodoro Braga. A exposição em Belém foi um sucesso e rendeu-lhe um convite, da parte de Lemos, para pintar uma obra que retratasse a fundação da cidade. O artista, então, voltou à Europa para passar dois anos, dessa vez em Portugal, onde pesquisaria nos documentos dos Arquivos ultramarinos os dados referentes

\footnotetext{
${ }^{10}$ file:///C:/Documents\%20and\%20Settings/admin/Meus\%20documentos/\%B0Edilson/web/ dezenovevinte.htm Acesso ao site, dia $1^{\circ}$ de março de 2007

${ }^{11} \mathrm{http}: / /$ www.designbrasil.org.br/portal/almanaque/enciclopedia.jhtmlindice $=\mathrm{V}$ Acesso ao site em $1^{\circ}$ de março de 2007

12 SARGES, Maria de Nazaré. Memórias do velho intendente: Antonio Lemos. Tese de Doutorado. Campinas: UNICAMP, 1998.
} 
à encomenda que recebera. Obstinado, em dois anos, Theodoro Braga produziu a obra A Fundação da Cidade de Belém, ${ }^{13}$ tela de grande extensão, inaugurada em dezembro de 1908, durante grande festa no foyer do Teatro da Paz, evento que contou com a presença das pessoas mais influentes da cidade.

Pela qualidade de sua obra e pelo prestígio alcançado junto a Lemos e à sociedade belenense, Theodoro Braga passou a ser o artista mais requisitado quando o assunto eram as artes plásticas. Por essa razão, chamou para si a responsabilidade de propor mudanças sobre o modo de fazer arte na Amazônia, principalmente na cidade de Belém, no início do século XX. Duas atitudes suas seriam fundamentais nessa mudança: em primeiro lugar, os convites feitos aos artistas brasileiros para realizarem mais exposições na cidade, já que um considerável número de artistas estrangeiros expunha ali suas obras, atraídos pelo fervor cultural da região, como Antonio Parreiras, Benedito Calixto, Oscar Pereira da Silva, João Batista da Costa. E, em segundo, o incentivo à formação crítica e estética de crianças e adolescentes, promovendo, no período de 1908 a 1920, exposições de trabalhos artísticos produzidos no ambiente escolar, experiência que marca sua caminhada como artista-pensador da formação de artistas e artífices do desenho, da pintura, das artes decorativas em geral.

\section{Marcos do percurso intelectual e artístico}

A partir de 1908, quando fixou residência em Belém, Theodoro Braga iniciou um período de grande produção artística e literária, dedicando-se, principalmente, a pinturas com temas históricos e retratos, e a obras sobre o ensino das artes visuais e sobre a arte decorativa utilizada pelos índios da Amazônia.

Desse período (1908-1921), suas obras mais importantes são:

Nas artes plásticas:

- A Fundação da Cidade de Belém - óleo sobre tela. Fonte: MABE - 1908;

- Cabega de mameluco Baroray - óleo sobre tela - s/medida. Fonte: Museu Paulista - 1911;

- Cabeça de mameluco Maracaty — óleo sobre tela - s/medida. Fonte: Museu Paulista - 1911;

- Portrait - óleo sobre tela - 73 X 60. Fonte: MEP - 1912;

- Presidente da República Hermes da Fonseca - óleo sobre tela - 82 X 65. Fonte: MEP - 1910;

- Retrato do Senador Antônio Lemos - óleo sobre tela - sem medida. Fonte: IHGP - 1910;

${ }^{13}$ BRAGA, Theodoro. "A fundação da cidade de Belém" - Óleo sobre tela - 226 x $511 \mathrm{~cm}$ - 1908 Fonte: Museu de Arte de Belém 
- Aparição a São Lucas - óleo sobre tela - 44 X 93. Fonte: MEP - 1903;

- Captação D'água - óleo sobre tela - Sem medida. Fonte: Museu de Arte de Belém - 1905;

- Padre Antonio Vieira na reducãa das tribos do Marajó, em 1657 - óleo sobre tela - sem medida. Fonte: Instituto Histórico de Alagoas

- Ex-libris Paraenses (publicado em 1910);

- Revista "O Paraense" - caricaturas e charges feitas por Theodoro Braga (publicado em1909);

- A Planta Brasileira (copiada do natural) aplicada à ornamentação - desenhos aquarelados. Fonte: Biblioteca Mário de Andrade - 1905);

\section{$\mathrm{Na}$ literatura:}

- Obra de nacionalização da arte brasileira (publicado em 1914);

- Estudo heráldico - para criação dos escudos d'armas para os municípios paraenses (publicado em 1912);

- A Fundação da Cidade de Nossa Senhora de Belém do Pará - estudos e documentos para a execução da grande tela histórica pintada pelo autor e encomendada pelo benemérito intendente Antonio José de Lemos (publicado em 1908).

É importante ressaltar que, no período em que esteve em Belém, Theodoro Braga dirigiu o Instituto de Formação Profissional Lauro Sodré, oportunidade em que ensinou desenho artístico aos jovens internos, estimulando-os na criação original e com características regionais, evitando, assim, as cópias importadas. São desse período as Exposições Escolares, evento social bastante prestigiado pela sociedade local.

Em 1921, de volta ao Rio de Janeiro para exercer a função de professor livre docente da Escola Nacional de Belas Artes, dirigiu interinamente o Instituto de Formação Profissional João Alfredo ${ }^{14}$, onde também lecionava, procedendo como fizera em Belém: estimulava a livre criação no desenho artístico, segundo ele próprio, o principal incentivo para suas aulas. Ainda no Rio, participou de várias edições das Exposições Gerais de Belas Artes promovidas pela Escola Nacional de Belas Artes, tendo recebido vários prêmios em pintura e em arte decorativa.

Algumas obras de destaque desse período (1921-1924):

Nas artes plásticas:

- Vasos em cobre e latão, com decoração marajoara;

- Hymno Nacional Brasileiro - ilustrações em aquarela para a poesia, em comemoração ao primeiro centenário do Brasil (publicado em 1922);

Na literatura:

${ }^{14}$ BRAGA, Theodoro. Memória do Instituto Profissional João Alfredo. Rio de Janeiro: Estabelecimento Gráfico Santa Cruz, 1925. 210 pp. 
- O ensino do desenho nos cursos técnicos profissionais - conferências no Rio de Janeiro (publicado em 1925).

Provavelmente motivado pelo grande movimento nas artes na São Paulo pós Semana de Arte Moderna, Theodoro Braga se transfere para aquela cidade em 1925, indo participar da fundação da Escola de Belas Artes, instituição destinada à formação de crianças e adolescentes, e, juntamente com outros artistas como Mário de Andrade, Menotti Del Picchia, Oscar Pereira da Silva, Pedro Alexandrino, Benedito Calixto, participou da fundação da Academia de Belas Artes de São Paulo ${ }^{15}$, hoje Faculdade de Belas Artes de São Paulo.

Em São Paulo, participou do Conselho de Orientação Artística do Estado de São Paulo, de 1925 até sua morte, em setembro de 1953, tendo, a partir de 1934, participado de edições do Salão Paulista de Belas Artes, onde conquistou vários e significativos prêmios, razão por que Morais Rego (1972, p.54) afirma que, em São Paulo, Theodoro Braga teve seu mais importante desempenho como intelectual das artes.

Parte da produção em São Paulo (1925-1953):

- Périplo Máximo de Antonio Raposo Tavares - óleo sobre tela - s/ medida e s/d. Fonte: Pinacoteca do Estado de São Paulo;

- Anhanguera - óleo sobre tela - 224 X 148 - s/d. Fonte: Museu Paulista;

- Padre Alexandre de Gusmão - óleo sobre tela - 81X $71 \mathrm{~cm}$ - s/d. Fonte: Museu Paulista;

- Herói do Rio Formoso - s/medida e s/d. Fonte: Museu da UFPA;

- Primeiro feito da República no continente americano - óleo sobre tela 60,0 x 88,4 cm - 1937. Fonte: Museu Nacional de Belas Artes - Rio de Janeiro;

- Casa marajoara - residência no bairro de Perdizes, São Paulo, decorada com motivos marajoaras;

- Problemas usuais do Desenho Linear e Geométrico (publicado em 1927);

- O ensino das artes: tese para o Congresso de História Nacional (publicado em 1931);

- Andrea Mantegna - conferência realizada para comemorar o IV centenário do nascimento do imortal pintor da Renascença Italiana (publicado em 1931);

- A arte no Pará 1888-1918: retrospecto histórico dos últimos trinta anos (publicado em 1934);

- Arte decorativa: inspirada na flora, na fauna e nos motivos da cerâmica dos indígenas brasileiros (publicado em 1938);

- Obra de nacionalização da arte brasileira (publicado em 1941);

- A cerâmica decorada dos indígenas: álbum de sugestões de motivos ornamentais, desenhos de cerâmicas dos brasileiros que habitam a foz do Rio Amazonas em Marajó e no Cunani (publicado em 1942).

${ }^{15}$ BELAS ARTES, 75 anos. São Paulo: Faculdade de Belas Artes de São Paulo, 2001.

Escola de Belas Artes de São Paulo (EBASP). Solenidades comemorativas do $25^{\circ}$ aniversário da fundação da EBASP. São Paulo: EBA-SP, 1950.

Conselho de Orientação Artística do Estado de São Paulo e suas atividades (1932-1942). São Paulo: COA- São Paulo, 1942. 


\section{A obra de Theodoro Braga na arte brasileira}

A produção artística e intelectual de Theodoro Braga (1905-1935) situa-se na passagem do século XIX para o século XX, período de transição mas também de afirmação de novos paradigmas na arte nacional, notadamente por dois fatos: a consolidação de mestres da pintura como Rodolfo Amoedo, Eliseu Visconti, Oscar Pereira da Silva, Henrique Bernardelli, Antonio Parreiras, J.Wast Rodrigues, que exploravam em suas obras temáticas nacionalistas, e o surgimento de uma nova geração de artistas, como Tarsila do Amaral, Anita Malfatti, Cândido Portinari, Lasar Segall, Di Cavancanti e outros, que afirmavam seus valores e influências, inspirados nas vanguardas da arte moderna européia, confirmando as novas tendências da arte brasileira a partir dos anos 30 .

Certamente retornar ao Rio de Janeiro em 1921 foi para Theodoro Braga um grande desafio, uma vez que saía do Pará, onde participara da construção de um espaço cultural próspero mas que se esvaía diante do declínio do comércio da borracha e da ausência de Antonio Lemos, apoio político e financeiro necessário ao desenvolvimento de seu talento de artista e educador naquele lugar.

Mas diante da trajetória já percorrida, logo Theodoro Braga se reposiciona no Rio de Janeiro e, poucos anos depois, em São Paulo, percorrendo um caminho próprio que, se não chegou a alcançar a mesma popularidade que outros contemporâneos, acompanhou as transformações estéticas sem perder sua própria história - a de um pintor clássicoacadêmico, figura das mais expressivas do clássico da pintura brasileira, como apontam Élide Monzenglio ${ }^{16}$ e Enzo Silveira ${ }^{17}$, mas também moderno, porque, além de pintar, escreve a história da Amazônia sob uma nova perspectiva ao posicionar-se como cuidadoso promotor de uma arte marcadamente nacionalista, reescrevendo, assim, a própria história da arte brasileira, na qual nas palavras de Figueiredo ${ }^{18}$ "o seu trabalho é uma espécie de pêndulo, de ponto eqüidistante entre o passado e o presente.”

${ }^{16}$ MONZENGLIO, Élide. Entrevista dada como ex-aluna da FBASP para a elaboração do livro dos 80 anos de fundação dessa entidade.

${ }^{17}$ SILVEIRA, Enzo. Os mais destacados pintores brasileiros autores de quadros históricos. Artigo: Diário Popular, São Paulo, 02/03/1975.

${ }^{18}$ FIGUEIREDO, Aldrin. Memórias dos tempos de Landi: arte colonial e história republicana na Amazônia, 1888-1918. 


\section{Theodoro Braga: do discurso nacionalista à multiforme obra artística e intelectual \\ - O discurso nacionalista: bandeira e paixão}

É possível afirmar que o sentido mais presente na obra de Theodoro Braga, a principal bandeira de seu discurso, seja a nacionalização da arte brasileira. O brasileirismo do artista mostra-se recorrente na sua obra, chegando ao ponto de produzi-la quase que totalmente com base nessa temática, como lemos no Catálogo do XVIII Salão de Belas Artes de São Paulo, de 195319:

...e o extraordinário em Theodoro Braga é que quanto mais o seu espírito se universalizava, mais o seu temperamento de artista se abrasileirava.

[...] essa preocupação de brasileirismo vai daí por diante se constituir num leit-motiv. A nacionalização de nossa arte se transforma em uma quase obsessão. Busca elementos na flora e na fauna brasileiras e ainda nas composições de nossos índios, para a campanha que passa a desenvolver em prol da arte decorativa aplicada.

Morais Rego destaca que Theodoro Braga foi "um pintor que sonhou ver coisas velhas sob ângulos novos e que soube dar um cunho nacionalista a sua obra", ressaltando, assim, a renovação que o artista buscava ao pensar a arte brasileira no seu tempo e projetá-la para o futuro. E mesmo trocando a Amazônia pela selva de pedra paulistana, manteve-se tão amazônida quanto antes.

Acadêmico ou moderno, o fato é que Theodoro Braga buscou na sua arte uma maneira de olhar por meio de uma cruzada de amor pela terra em que vivia, o Brasil. Alimentado pela estética nacionalista do Romantismo europeu ${ }^{20}$, Theodoro Braga primava pela pesquisa, resgate e exaltação dos elementos regionais e populares por meio da cultura, buscando, conforme já defendia Angelo Agostini ${ }^{21}$ no final do século XIX, o fim das idealizações da história e da mitologia sobre o Brasil e captando a paisagem do país, para que finalmente se pudesse constituir uma escola efetivamente nacionalista de pintura, traduzindo em arte a alma do povo brasileiro, como Alberto Nepomuceno e Heitor Villa-Lobos fizeram na música, Mário de Andrade e Portinari, na literatura e nas artes plásticas.

${ }^{19}$ XVIII Salão Paulista de Belas Artes. São Paulo: Galeria Prestes, 1953. (Homenagem póstuma a Theodoro Braga)

${ }^{20}$ PONTUAL, Roberto. Entre dois séculos. Rio de Janeiro: Ed. JB, 1967.

21 Angelo Agostini, (1843-1910). Nasceu na Itália e chegou ao Brasil em 1859, fixando-se em São Paulo. Foi pintor, caricaturista e crítico de artes plásticas, atividade que exerceu com conhecimento, fazendo uso de uma linguagem extremamente ferina e bem-humorada. 
Mantendo ou não um pé no passado romântico, ou o corpo no ufanismo republicano, ou no modernismo que se abria a sua frente, o fato é que Theodoro Braga, enquanto esteve vivo, respirou um sentido de liberdade que a nacionalização da arte brasileira proporcionaria, na qual acreditava e pela qual lutava, ao investir na formação de artífices operários das fábricas e na educação artístico-estética das crianças, que, segundo ele, precisam de educadores com a tarefa de formar espíritos e ensinar os educandos a "serem cérebros que pensem, alma que quer e mãos que produzem conscientemente" e não meros copiadores de catálogos estrangeiros.

\section{- Arte decorativa com inspiração indígena: gozo para os sentidos}

Theodoro Braga se tornou um mestre na arte decorativa. Aplicado, conhecedor do assunto, vencedor de inúmeros prêmios e autor de um belo compêndio sobre decoração e ornamentação no Brasil, ensinou e fez escola por onde passou. No Pará, em 1905, Theodoro Braga pesquisou as formas geométricas das cerâmicas produzidas pelos índios da região da ilha do Marajó. No artigo "A arte decorativa entre os selvagens da foz do Amazonas" 22 , ele enaltece indígenas marajoaras ao reconhecer o legado artístico deixado para a humanidade em Joannes, na Ilha do Marajó e ressalta que "os indígenas do Marajó nos legaram a preocupação de um gožo para os sentidos, por meio de ornamentações graciosas e leves, de um prazer intelectual em se cercarem de elementos superiores às brutais e exclusivas necessidades da vida material". São documentos originais e abundantes do desenho decorativo em objetos de arte primitiva que enriquecem a arqueologia e a etnografia brasileira.

Tais estudos foram de tamanha relevância para a vida de Theodoro Braga que, na oportunidade que teve de construir sua residência em São Paulo, onde se fixou e trabalhou durante os 29 anos finais de sua vida, não se furtou a desenhá-la nos mínimos detalhes. Edificado no bairro de Perdizes, São Paulo, o "Retiro Marajoara" 23 é uma casa que mais parece um santuário amazônico na floresta de concreto, um poema de pedra e cal

\footnotetext{
22 BRAGA, Theodoro. A arte decorativa entre os selvagens da foz do Amazonas. Revista do Instituto Histórico e Geográfico do Pará. Belém: Vol 1- PA/ 1932. p.49-51.

${ }^{23}$ REVISTA ILUSTRAÇÃO BRASILEIRA. Casa Marajoara de Theodoro Braga. São Paulo: Sociedade Anônima "O Malho", n 26, 1937.
} 
escrito com paciência e sabedoria. Utilizando a linha singela do estilo colonial, Theodoro Braga executou os motivos ornamentais inspirados na decoração da cerâmica marajoara, forjando o ferro, o vidro, a madeira, o cobre, a pintura e o ladrilho com marcas daquele estilo indígena. Foi ele próprio também que desenhou das grades de ferro, vitrais, móveis e lustres à decoração mural e tapetes, e mesmo à ornamentação dos frisos e painéis em relevo que revestiam marcadamente a fachada principal, detalhes retirados posteriormente por algum proprietário.

Homem de cultura polimorfa, espírito aberto aos mais variados departamentos do saber, artista de paleta diversificada, curioso e inquieto, que lia e investigava a respeito de tudo, procurava estar a par das transformações, numa ânsia de saber ${ }^{24}$. Por onde passou, Theodoro Braga deixou sua marca de vigor e honradez, com uma obra vibrante e criativa. $\mathrm{Na}$ arte que lhe coube fazer e em tudo, foi um mestre, transformando suas idéias em formas concretas. Um visionário que queria ver um país que valorizasse sua arte e sua cultura, que formasse principalmente as crianças e os operários. Theodoro Braga não mediu esforços para ensinar e mostrar as pessoas que fazer arte é algo que surge de dentro e ultrapassa o ser humano, transformando-o para melhor. E cremos que Theodoro Braga conseguiu seu intento.

${ }^{24}$ XVIII Salão Paulista de Belas Artes. São Paulo: Galeria Prestes, 1953. 